\title{
Increasing the revenues from automatic milking by using individual variation in milking characteristics
}

\author{
G. André,${ }^{* 1}$ P. B. M. Berentsen,† B. Engel,‡ C. J. A. M. de Koning, ${ }^{\star}$ and A. G. J. M. Oude Lansink† \\ ${ }^{*}$ Animal Sciences Group, Wageningen University and Research Centre, PO Box 65, 8200 AB Lelystad, the Netherlands \\ †Business Economics Group, Wageningen University and Research Centre, PO Box 8130, 6700 EW Wageningen, the Netherlands \\ $\ddagger$ Biometris, Wageningen University and Research Centre, PO Box 100, 6700 AC Wageningen, the Netherlands
}

\section{ABSTRACT}

The objective of this study was to quantify individual variation in daily milk yield and milking duration in response to the length of the milking interval and to assess the economic potential of using this individual variation to optimize the use of an automated milking system. Random coefficient models were used to describe the individual effects of milking interval on daily milk yield and milking duration. The random coefficient models were fitted on a data set consisting of 4,915 records of normal uninterrupted milkings collected from 311 cows kept in 5 separate herds for $1 \mathrm{wk}$. The estimated random parameters showed considerable variation between individuals within herds in milk yield and milking duration in response to milking interval. In the actual situation, the herd consisted of 60 cows and the automatic milking system operated at an occupation rate (OR) of $64 \%$. When maximizing daily milk revenues per automated milking system by optimizing individual milking intervals, the average milking interval was reduced from $0.421 \mathrm{~d}$ to $0.400 \mathrm{~d}$, the daily milk yield at the herd level was increased from 1,883 to 1,909 $\mathrm{kg} / \mathrm{d}$, and milk revenues increased from $€ 498$ to $€ 507 / \mathrm{d}$. If an OR of $85 \%$ could be reached with the same herd size, the optimal milking interval would decrease to $0.238 \mathrm{~d}$, milk yield would increase to $1,997 \mathrm{~kg} / \mathrm{d}$, and milk revenues would increase to $€ 529 / \mathrm{d}$. Consequently, more labor would be required for fetching the cows, and milking duration would increase. Alternatively, an OR of $85 \%$ could be achieved by increasing the herd size from 60 to 80 cows without decreasing the milking interval. Milk yield would then increase to $2,535 \mathrm{~kg} / \mathrm{d}$ and milk revenues would increase to $€ 673 / \mathrm{d}$. For practical implementation on farms, a dynamic approach is recommended, by which the parameter estimates regarding the effect of interval length on milk yield and the effect of milk yield on milking duration are updated

Received May 12, 2009.

Accepted September 23, 2009.

${ }^{1}$ Corresponding author: geert.andre@wur.nl regularly and also the milk production response to concentrate intake is taken into account.

Key words: economic evaluation, milking duration, milking interval, random coefficient model

\section{INTRODUCTION}

Presently, on approximately 5,000 farms worldwide, cows are milked using an automatic milking system (AMS), and this number is rapidly increasing. Although an AMS requires a greater investment than a conventional system, increased milk yields per cow and reduced labor costs may result in lower costs per kilogram of milk produced (de Koning and Rodenburg, 2004). From the point of economic efficiency of the AMS, maximizing milk production per AMS is crucial (Sonck and Donkers, 1995).

Daily milk yield per cow increases with the number of milkings per day (de Koning and Ouweltjes, 2000). On the other hand, the sum of milking time of all cows in the herd is restricted by the capacity of the AMS. The capacity of the AMS is defined as the time an AMS is available for milking per 24-h day. This capacity can also be expressed as an occupation rate (OR), defined as the percentage of hours the milking system is available per day. When the AMS, for example, has an OR of $70 \%$, the AMS is available $16.8 \mathrm{~h} / \mathrm{d}$ for milking the cows, whereas the remaining $7.2 \mathrm{~h}$ are reserved for rinsing and cleaning the AMS, for handling nonmilking visits, and for idle time. Inclusion of idle time is necessary to avoid crowding the cows waiting to be milked, which could easily lead to the cows holding back from visiting the AMS. Given the OR, the question is then how to allocate the total time available for milking to the individual cows in the herd such that milk revenues per day of the AMS are maximized. Allocation of time is made operational by setting minimum values for the milking interval (the time between 2 milkings). In practice, simple guidelines based on daily milk production and parity are used for this, but there might be possibilities for fine tuning. Milk flow (the amount of milk leaving the udder per time unit) and the relationship between number of milkings per day and daily milk production 


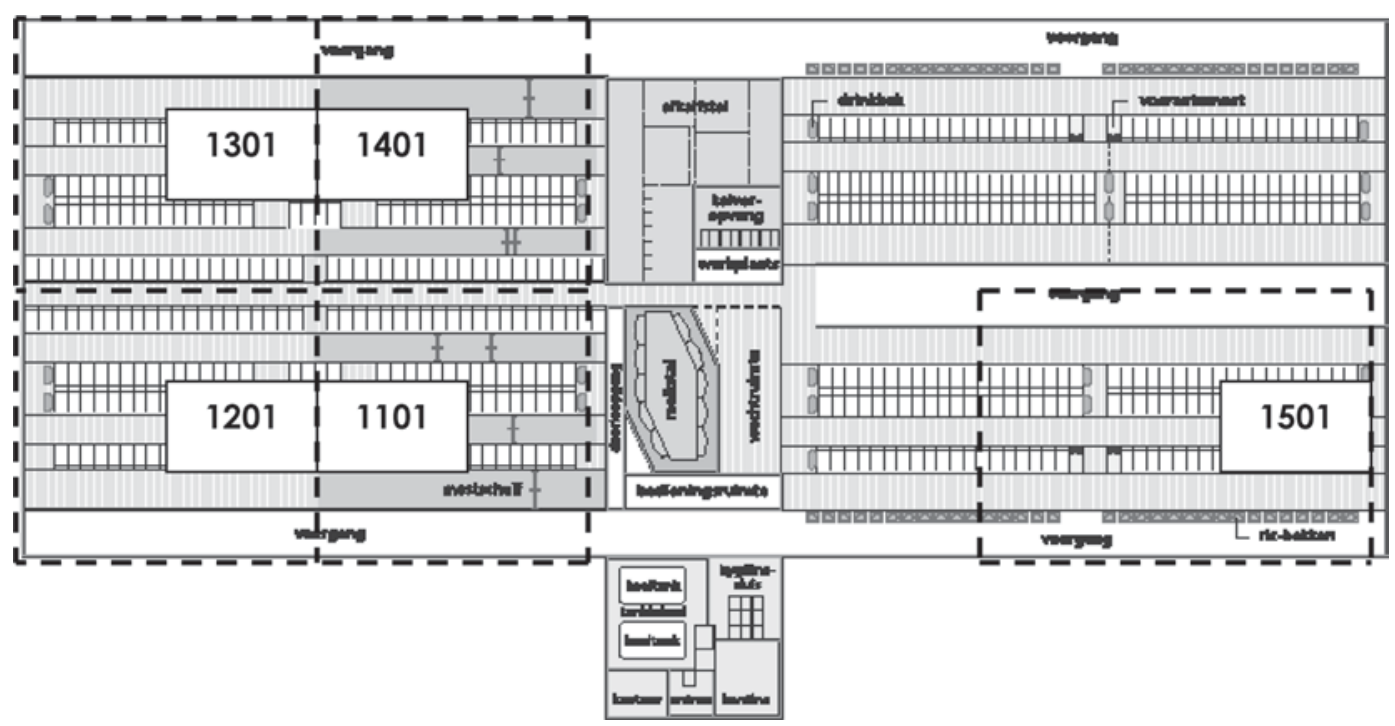

Figure 1. Layout of the De Waiboerhoeve research farm. The numbers 1101 to 1501 refer to the different herds and indicate the locations of the automated milking systems.

vary considerably between cows (Ipema and Hogewerf, 2004). These milking characteristics are hereditary, but also depend on parity and lactation stage. By continuous monitoring of the automatic milking process, milking characteristics per cow can be determined on a daily basis, and can be used to optimize the allocation of total milking time to individual cows.

Previous research in this area was focused on determining total milk production per AMS. Using simple guidelines for time allocation, de Koning and Ouweltjes (2000) assessed a potential total milk production ranging between 600,000 and $750,000 \mathrm{~kg}$ of milk/yr. For 31 Dutch farms with an AMS in 2003, Bijl et al. (2007) found an average milk production of $494,442 \mathrm{~kg}$ of milk/ yr per AMS. They concluded that the capacity of most of the AMS was not yet fully used and that there was scope for growth within the existing capacity.

The objective of this study was twofold. The first objective was to quantify the variation between individuals in milk yield response to milking interval and the corresponding individual variation in milking duration, which also includes variation in milk flow. The second objective was to study the potential economic prospects of using individual variation in milking characteristics, including milk price, by maximizing daily milk revenues of an AMS.

\section{MATERIALS AND METHODS}

\section{Data}

Data used in this study were obtained from the De Waiboerhoeve research farm of the Animal Sciences
Group in Lelystad, a dairy farm with Holstein-Friesian cows. Within this farm, 5 groups of approximately 64 lactating cows per group were managed as different herds and housed in separated sections, 4 herds were housed in 4 adjacent sections, and 1 herd was housed in a separated section of a free stall (Figure 1). Apart from differences in floor type, housing conditions were similar for all herds.

Cows from each herd were milked with a single-stall AMS (Astronaut A2, Lely, Rotterdam, the Netherlands) with an average production of $657,000 \mathrm{~kg}$ of milk/yr per robot. The vacuum level was $48 \mathrm{kPa}$ and the pulsation ratio was 65:35. The cows received 1 to 6 $\mathrm{kg}$ of concentrates during milking, depending on their production level. Water and a partially mixed feeding ration were available ad libitum. The partially mixed ration was a mixture composed of (DM basis) $8.0 \mathrm{~kg}$ of grass silage, $7.0 \mathrm{~kg}$ of corn silage, $0.4 \mathrm{~kg}$ of grass seed hay, $1.3 \mathrm{~kg}$ of sugar beet pulp (pressed, ensiled), $2.0 \mathrm{~kg}$ of soybean meal, $1.5 \mathrm{~kg}$ of wheat meal (fine), and 0.2 $\mathrm{kg}$ of minerals.

The data were real-time process data registered by the AMS. At each milking, milk yield, milking duration (time taken from entry to exit of the AMS, i.e., total box-visiting time), and milking interval (time between the beginning of 2 consecutive milkings) were observed. The actually realized milking intervals resulted from settings for the admittance interval advised by the manufacturer (Table 1) and the cow collection strategy of the herdsman. Cows that exceeded a 12-h interval were fetched at 3 different times per day.

Data were collected over a period of 1 wk from April 30, 2007, to May 6, 2007. Because this is only a short 
Table 1. Admittance interval settings for different categories of dairy cows milked by an automatic milking system ${ }^{1}$

\begin{tabular}{llc}
\hline $\begin{array}{l}\text { Primiparous milk } \\
\text { yield }(\mathrm{kg} / \mathrm{d})\end{array}$ & $\begin{array}{l}\text { Multiparous milk } \\
\text { yield }(\mathrm{kg} / \mathrm{d})\end{array}$ & $\begin{array}{l}\text { Admittance } \\
\text { interval }(\mathrm{d})\end{array}$ \\
\hline$M \leq 20$ & $M \leq 25$ & 0.40 \\
$20<M \leq 27$ & $25<M \leq 33$ & 0.29 \\
$27<M \leq 30$ & $33<M \leq 40$ & 0.25 \\
$M>30$ & $M>40$ & 0.22 \\
\hline
\end{tabular}

${ }^{1} M=$ milk yield.

period, it was assumed that some cow characteristics, such as feed intake and efficiency, remained constant. The data set consisted of 4,915 records of normal, uninterrupted milkings following normal, uninterrupted milkings. Deviating observations caused by registration errors were excluded from the data set. In total, 311 cows (122 primiparous and 189 multiparous cows) were observed. Descriptive statistics of the data, comprising herd size $(H)$, milk yield per milking ( $M$, in $\mathrm{kg}$ ), milking duration per milking ( $D$, in min), length of the preceding milk interval ( $I$, as a fraction of the day; hours/24), and derived statistics, such as daily milk yield $(M / I)$ per cow, are presented in Table 2.

\section{Effect of Milking Interval on Milk Yield and Milking Duration per Milking}

Milk yield per milking depends on the length of the preceding interval; this is referred to as the interval sensitivity. Stelwagen (2001) found that compared with 2 milkings per day, milking 3 times a day increased milk yield by $18 \%$, whereas milking once per day decreased milk output by $20 \%$. Ouweltjes (1998) showed that milk production per hour was higher for short intervals (during the daytime) than for long intervals (during the nighttime) when cows were milked 2 times per day. Delamaire and Guinard-Flament (2006) found that daily milk yield decreased curvilinearly with increasing intervals from 8 to $24 \mathrm{~h}$. France and Thornley (1984) used a nonlinear Michaelis-Menten curve to describe the decreasing milk secretion rate by increasing intervals, attributable to udder filling, which in turn depends on the storage capacity of the udder. Based on these insights from the literature, the relationship between milk yield per milking $(M)$ and interval length $(I)$ was approximated by a quadratic curve, $M=B_{1} I+B_{2} I^{2}$, with $B_{1}$ and $B_{2}$ being the coefficients for the linear and quadratic effects of interval length, respectively. There is no intercept in the model, because at the beginning of the interval $(I=0)$ directly after milking, the udder is empty. The linear coefficient represents the milk secretion rate at the beginning of the interval, and the quadratic coefficient represents the interval sensitivity.

An entire milking consists of several phases. When the cow enters the AMS, time is needed for identification, udder preparation, and teat cup attachment. The required time for milking depends on the milk yield and flow rate of the individual cow (de Koning and Ouweltjes, 2000). After milking, the teat disinfection, cluster cleansing, and exit of the cow from the AMS

Table 2. Descriptive statistics for the data set

\begin{tabular}{|c|c|c|c|c|c|c|}
\hline Item & Variable & $\begin{array}{c}\text { Herd } 1101, \\
\text { solid concrete } \\
\text { floor }\end{array}$ & $\begin{array}{c}\text { Herd } 1201, \\
\text { slatted } \\
\text { concrete floor }\end{array}$ & $\begin{array}{l}\text { Herd } 1301, \\
\text { slatted } \\
\text { rubber floor }\end{array}$ & $\begin{array}{l}\text { Herd } 1401, \\
\text { solid rubber } \\
\text { floor }\end{array}$ & $\begin{array}{c}\text { Herd } 1501, \\
\text { slatted } \\
\text { concrete floor }\end{array}$ \\
\hline Herd size & $H$ & 63 & 62 & 61 & 59 & 66 \\
\hline Days in lactation & & 190 & 210 & 263 & 202 & 164 \\
\hline $\mathrm{SD}$ & & 114 & 122 & 138 & 109 & 120 \\
\hline Primiparous cows $(\%)$ & & 33 & 44 & 28 & 61 & 32 \\
\hline Parity & & 2.35 & 2.13 & 2.79 & 1.70 & 2.76 \\
\hline \multicolumn{7}{|l|}{ Per milking } \\
\hline Milk yield (kg/milking) & $M$ & 13.0 & 12.6 & 11.7 & 12.1 & 14.0 \\
\hline SD & & 3.66 & 3.40 & 4.18 & 3.20 & 4.55 \\
\hline Duration (min/milking) & $D$ & 6.76 & 6.21 & 6.31 & 5.54 & 6.44 \\
\hline $\mathrm{SD}$ & & 1.75 & 1.53 & 2.06 & 1.73 & 1.75 \\
\hline \multicolumn{7}{|l|}{ Per cow } \\
\hline Milking interval (d) & $I$ & 0.425 & 0.425 & 0.444 & 0.402 & 0.420 \\
\hline $\mathrm{SD}$ & & 0.109 & 0.098 & 0.113 & 0.078 & 0.110 \\
\hline Milk yield (kg/cow per day) & $M / I$ & 30.6 & 29.6 & 26.4 & 30.1 & 33.3 \\
\hline SD & & 11.7 & 9.3 & 11.4 & 9.5 & 11.5 \\
\hline Duration (min/cow per day) & $D / I$ & 15.9 & 14.6 & 14.2 & 13.8 & 15.3 \\
\hline \multicolumn{7}{|l|}{ Use of AMS capacity $^{1}$} \\
\hline Milkings (no./d) & $H / I$ & 148 & 146 & 137 & 147 & 157 \\
\hline Duration $(\mathrm{h} / \mathrm{d})$ & $H D / 60 I$ & 16.7 & 15.1 & 14.4 & 13.6 & 16.8 \\
\hline Occupation rate $(\%)$ & & 69 & 63 & 60 & 57 & 70 \\
\hline Milk yield $(\mathrm{kg} / \mathrm{d})$ & $H M / I$ & 1,928 & 1,835 & 1,610 & 1,776 & 2,198 \\
\hline
\end{tabular}

${ }^{1} \mathrm{AMS}=$ automatic milking system. 


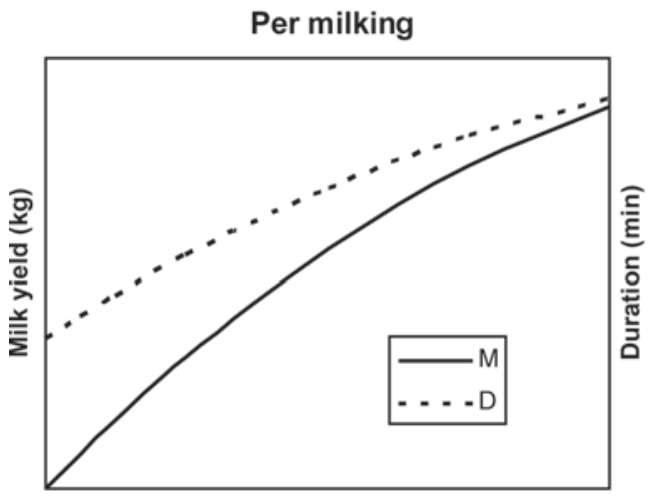

Interval (h)

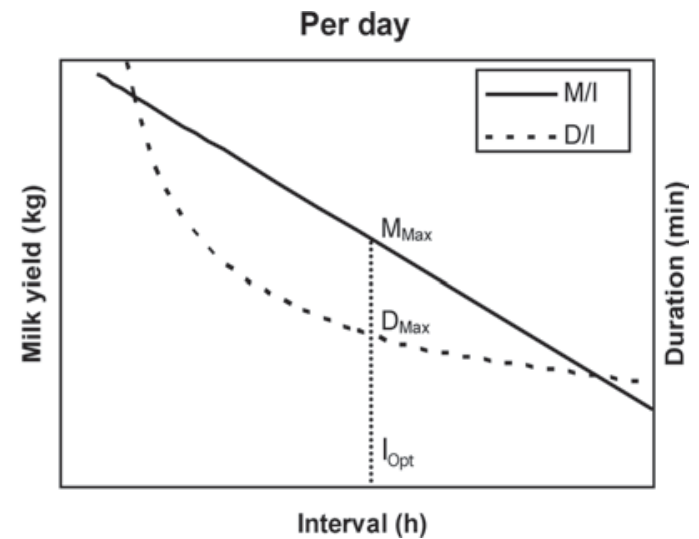

Figure 2. Relation between milk yield ( $M$; solid line, left axis) and milking duration ( $D$; dashed line, right axis) per milking (left figure) and per day (right figure) with interval length $I$. The right figure shows the maximal milking duration $D_{\text {Max }}$, determining the optimal interval length $I_{O p t}$ and the maximal daily milk yield per day $M_{M a x}$.

take time. Therefore, it was assumed that milking duration $(D)$ consists of a constant proportion of time and a variable proportion of time depending on milk yield, $D$ $=A_{0}+A_{1} M$, with $A_{0}$ being the intercept and $A_{1}$ being the slope.

The effect of milking interval on milk yield per milking and the effect of milk yield per milking on milking duration per milking are displayed in Figure 2. Dividing milk yield per milking and milking duration per milking by the interval length results in milk yield per day and milking duration per day. Milk yield per day increases linearly as the length of the interval between milkings decreases (increasing milking frequency), but milking duration per day increases exponentially. The potential increase in milking duration is restricted by the available capacity of the AMS. During the day, a certain amount of time is needed by the AMS for rinsing and cleaning, handling interrupted milkings, and additional nonmilking visits. Furthermore, some more idle time is needed for the AMS to function well. The remaining time per day is the available capacity of the AMS for milking (i.e., the maximum milking duration). The maximum milking duration $\left(D_{M a x}\right)$ in relation to herd size determines the optimal length of the milking interval $\left(I_{O p t}\right)$ and, consequently, the maximal daily milk yield $\left(M_{M a x}\right)$.

\section{Statistical Models Incorporating Individual Effects}

Yield per Milking. The coefficients $B$ were formulated in more detail, distinguishing between systematic population effects and random individual effects. Because daily milk production at a certain moment during lactation depends on feeding and energy status (Vetharaniam et al., 2003) and parity, the systematic effects in coefficients $B$ comprise main effects and in- teraction terms for herd and parity. The coefficients $B$ were assumed to be constant (for each cow) during the short period of $1 \mathrm{wk}$ of data collection. The model for milk yield per milking is given in model 1 :

$$
\begin{aligned}
& M_{i j k l}=B_{1 i k l} I+B_{2 i k l} I^{2}+\varepsilon_{i j k l}=\left(\beta_{1}+\kappa_{1 k}+\lambda_{1 l}+\gamma_{1 k l}\right. \\
& \left.+b_{1 i}\right) I+\left(\beta_{2}+\kappa_{2 k}+\lambda_{2 l}+\gamma_{2 k l}+b_{2 i}\right) I^{2}+\varepsilon_{i j k l},
\end{aligned}
$$

with $M_{i j k l}$ being the yield at milking $j$ of cow $i$ from herd $k$ with parity $l(\mathrm{~kg}) ; I$ being the interval length (day); $\beta_{1}$ being the coefficient linear interval effect, representing milk production rate at the beginning of the interval $(\mathrm{kg} / \mathrm{d}) ; \kappa_{1 k}$ being the effect of herd $k$ on the coefficient of the linear interval length $(\mathrm{kg} / \mathrm{d}) ; \lambda_{1 l}$ being the effect of parity $l$ on the coefficient of the linear interval length $(\mathrm{kg} / \mathrm{d}) ; \gamma_{1 k l}$ being the interaction effect of herd $k$ and parity $l(\mathrm{~kg} / \mathrm{d})$ on the coefficient of the linear interval length $(\mathrm{kg} / \mathrm{d})$; and $b_{1 i}$ being the individual random effect on the coefficient for the linear interval length for cow $i(\mathrm{~kg} / \mathrm{d})$. Likewise, for the coefficient $B_{2}$ of the quadratic interval effect, systematic effects $\beta_{2}, \kappa_{2 k}, \lambda_{2 l}$, and $\gamma_{2 k l}$ and individual random effects $b_{2 i}$ were introduced. Finally, $\varepsilon_{i j k l}$ is the residual term.

The individual random effects $b_{1}$ and $b_{2}$ of a cow were assumed to follow a bivariate normal distribution, with mean 0 and covariance matrix $\Sigma_{B}$. Individual random effects of different animals were assumed to be independent. Residuals $\varepsilon$ were assumed to be independently normally distributed, with mean 0 and variance $\sigma_{\varepsilon}^{2}$. Random effects $b$ and $\varepsilon$ were assumed to be mutually independent. The cornerstone parameterization was adopted, which expressed the differences between herds and parities relative to primiparous cows of herd 1101; that is, 


$$
\kappa_{11}=\lambda_{11}=\gamma_{11 l}=\gamma_{1 k 1}=\kappa_{21}=\lambda_{21}=\gamma_{21 l}=\gamma_{2 k 1}=0 .
$$

Duration per Milking. Similarly, the coefficients $A$ were formulated in more detail, incorporating systematic effects for parity and herd and individual random effects. Again, in the short data collection period of 1 wk, intercept $A_{0}$ and slope $A_{1}$ were assumed to be constant. The model for duration per milking is given in model 2:

$$
\begin{gathered}
D_{i j k l}=A_{0 i}+A_{1 i} M+\delta_{i j k l}= \\
\left(\alpha_{0}+\tau_{0 k}+v_{0 l}+\eta_{0 k l}+a_{1 i}\right) M+\delta_{i j k l},
\end{gathered}
$$

with $D_{i j k l}$ being the duration of milking $j$ of cow $i$ in herd $k$ with parity $l(\min ) ; M$ being the yield per milking $(\mathrm{kg}) ; \alpha_{0}$ being the intercept $(\min ) ; \tau_{0 k}$ being the fixed effect of herd $k$ on the intercept (min); $v_{0 l}$ being the fixed effect of parity $l$ on the intercept (min); $\eta_{0 k l}$ being the interaction effect of herd $k$ and parity $l$ on the intercept (min); and $a_{0 i}$ being the individual random effect on the intercept for cow $i$ (min). Likewise, for the slope $A_{1}$, the systematic effects $\alpha_{1}, \tau_{1 k}, v_{1 l}$, and $\eta_{1 k l}$ and the individual random effects $a_{1 i}$ were introduced. Finally, $\delta_{i j k l}$ is the residual term.

The individual random effects of a cow, $a_{0}$ and $a_{1}$, were assumed to follow a bivariate normal distribution, with mean 0 and covariance matrix $\Sigma_{A}$. Individual random effects of different animals were assumed to be independent. Residuals $\delta$ were assumed to be independently normally distributed, with mean 0 and variance $\sigma_{\delta}^{2}$. Random effects $a$ and $\delta$ were assumed to be mutually independent. Again, systematic effects were expressed relative to primiparous cows of herd 1101:

$$
\tau_{01}=\tau_{11}=v_{01}=v_{11}=\eta_{0 k l}=\eta_{011}=\eta_{1 k 1}=\eta_{11 l}=0 .
$$

Parameters were estimated by REML (Searle et al., 1992). Calculations were performed with Genstat (Genstat Committee, 2006). Only statistically significant ( $P$ $<0.05$; Wald test) parameters were retained in the model. Residual analysis was performed to detect outliers and to check model assumptions such as normality and temporal independence of residuals.

Individual cow parameters $A_{i}$ and $B_{i}$ were estimated by $\hat{A}_{i}$ and $\hat{B}_{i}$ : the BLUP (Robinson, 1991). These estimates comprise the relevant systematic effects of herd and parity and the individual random effects.

\section{Optimization of AMS Capacity}

Individual optimal milking intervals $I_{O p t, i}$ were found by solving the nonlinear programming problem of maximizing the daily milk revenues $\sum_{i} S_{i}$ subject to the constraint that the total milking duration per day $\sum_{i} \hat{D}_{i} / I$ cannot exceed the available capacity of the AMS, $D_{\text {Max }}$. Duration and also milk yield per milking were divided by interval length to achieve the duration and milk yield per day. Note that dividing by the interval length is equivalent to multiplying by milking frequency. The individual optimal milking intervals were found by solving the nonlinear programming problem with GAMS (Rosenthal, 2006). Daily milk revenues were computed as the sum of the individual milk revenues, which is a function of individual milk yield and individual milk price, $\pi_{M, i}$. The objective function was

$$
\sum_{i} S_{i}=\sum_{i}\left\{\pi_{M, i} \hat{M}_{i} / I\right\}=\sum_{i}\left\{\pi_{M, i}\left(\hat{B}_{1, i}+\hat{B}_{2, i} I\right)\right\}
$$

with $S_{i}$ being milk revenue of cow $i(€ / \mathrm{d}) ; \pi_{M, i}$ being the individual milk price of cow $i(€ / \mathrm{kg}) ; \hat{M}_{i} / I$ being the predicted milk yield of cow $i(\mathrm{~kg} / \mathrm{d})$; and $\hat{B}_{1, i}$ and $\hat{B}_{2, i}$ being individual parameter estimates of cow $i$ (see model 1).

Calculation of the individual milk price was based on the deviation of the individual fat $\left(F_{i}\right)$ and protein $\left(P_{i}\right)$ content from the averaged content at the herd level, fat at $4.133 \%$ and protein at $3.416 \%$ :

$$
\pi_{M, i}=1.06\left\{\bar{\pi}_{M}+\pi_{F}\left(F_{i}-4.133\right)+\pi_{P}\left(P_{i}-3.416\right)\right\} / 100,
$$

with $\bar{\pi}_{M}$ being the averaged milk price at the herd level; $\pi_{F}=2.78$ being the fat price $(€ / \mathrm{kg})$; and $\pi_{P}=$ 5.49 being the protein price $(€ / \mathrm{kg}$; Friesland Foods, price levels as of May 2007). The factor 1.06 is the rate of value-added tax.

The constraint for total milking duration was

$$
\sum_{i} \hat{D}_{i} / I=\sum_{i}\left\{\hat{A}_{0, i} I^{-1}+\hat{A}_{1, i}\left(\hat{B}_{1, i}+\hat{B}_{2, i} I\right)\right\} \leq D_{M a x},
$$

with $\hat{D}_{i} / I$ being the predicted milking duration of cow $i(\min / \mathrm{d}) ; \hat{A}_{0, i}$ and $\hat{A}_{1, i}$ being individual parameter estimates of cow $i$ (see model 2); and $D_{\text {Max }}$ being the maximum total milking duration $(\mathrm{min} / \mathrm{d})$.

Individual optimal milking intervals were restricted such that cows were milked at least once per day (i.e., $0<I<1)$. Results for the individual optimal intervals were calculated for each herd separately given the herd size in the actual situation. 
Table 3. Parameter estimates and standard errors for milk yield per milking

\begin{tabular}{lcc}
\hline Parameter & Estimate & SE \\
\hline Systematic part of the model & & \\
Linear interval effect $\left(\beta_{1}\right)$ & 29.9 & 1.5 \\
Linear interval effect of herd $\left(\kappa_{1 k}\right)$ & 0 & - \\
$\quad$ Herd 1101 & -0.24 & 1.98 \\
Herd 1201 & -2.03 & 1.42 \\
Herd 1301 & +2.74 & 2.04 \\
Herd 1401 & +5.82 & 1.95 \\
Herd 1501 & 0 & - \\
Linear interval effect of parity $\left(\lambda_{1 l}\right)$ & 5.09 & 1.02 \\
Primiparous & -8.72 & 1.26 \\
Multiparous & 0 & \\
Quadratic interval effect $\left(\beta_{2}\right)$ & +1.87 & 1.79 \\
Quadratic interval effect of herd $\left(\kappa_{2 k}\right)$ & -0.61 & 1.67 \\
Herd 1101 & -2.75 & 1.88 \\
Herd 1201 & -3.27 & 1.74 \\
Herd 1301 & & \\
Herd 1401 & & \\
Herd 1501 & 212 & 19 \\
Random part of the model & & \\
Variance linear effect $\left(\sigma_{B 1}^{2}\right)$ & 86.0 & 12.9 \\
Variance quadratic effect $\left(\sigma_{B 2}^{2}\right)$ & & \\
& & \\
Residual variance $\left(\sigma_{\delta}^{2}\right)$ & -0.615 & 0.013 \\
Correlation of linear with quadratic $\left(\rho_{B 01}\right)$ & & \\
\hline
\end{tabular}

The $D_{\text {Max }}$ was set to the milking duration for each herd, achieved in the actual situation (Table 2). Individual optimal milking intervals were calculated for the actual situation to demonstrate the effect of individual optimization. Subsequently, the actual situation was compared with increasing settings for $D_{\text {Max }}(1,008$ to 1,224 $\mathrm{min} / \mathrm{d}$, with steps of $72 \mathrm{~min}$ ) according to $4 \mathrm{OR}$ of the AMS: $70,75,80$, and $85 \%$. This demonstrates the effect of increasing OR in combination with individual optimization.

\section{RESULTS AND DISCUSSION}

\section{Yield per Milking}

Parameter estimates and standard errors for the effects of milking interval on yield per milking are given in Table 3. Terms that were not statistically significant were removed from the model. The systematic part of the model describes the average effects at the population level. The linear interval effect, representing the milk production rate at the beginning of the interval, differed significantly between herds: herd 1301 had the lowest production rate and herd 1501 had the highest, which is in agreement with days in lactation (Table 2 ). The production rate for multiparous cows was significantly higher than that for primiparous cows. The quadratic interval effect represents interval sensitivity, and it differed significantly between herds: herd
1501 displayed the greatest sensitivity and herd 1201 displayed the least. This difference may be explained by the stage of lactation and, consequently, the milk yield. The effect of parity on interval sensitivity was not significant. There were no significant interactions between parity and herd, and equal effects of parity among herds were assumed.

The average relationship between milking interval and yield per milking is shown per herd for primiparous and multiparous cows separately in Figure 3. The random part of the model for milk yield per milking (model 1) represents the individual variation in the cow coefficients for linear and quadratic effects of milking interval (i.e., the variation between individual curves) and the residual variation (i.e., the variation between cows around their curves). Variation was expressed in terms of 3 variances (variance components), representing variation between cows in coefficients of linear and quadratic terms (i.e., linear increase and curvature) and variation within cows. Figure 4 demonstrates that there was considerable variation between individuals in milk yield per milking. The variation was mainly related to the linear effect of interval (initial milk secretion rate) and, to a smaller extent, to the quadratic effect (curvature, interval sensitivity).

The assumption of a zero intercept was checked by fitting model 1 for milk yield per milking, expanded with an intercept. The additional intercept did not differ statistically significantly from 0 . Moreover, the model without an intercept produced more stable parameter estimates. Residual analysis by testing the autocorrelation between the residuals within a cow showed no significant interdependency.

\section{Duration per Milking}

Table 4 contains the parameter estimates and standard errors for the effects of milk yield on milking duration. In the systematic part of the model, the intercept differed significantly between herds: herd 1101 showed the highest intercept and herd 1401 showed the lowest. The linear coefficient did not differ significantly between herds. Parity did not have a significant effect on intercept and slope, and there were no significant interactions.

Again, variance components represent the variation in intercept and slope between individuals and the residual variation. Figure 5 shows considerable variation between individuals that was not explained by parity and herd.

\section{Optimization of AMS Capacity}

Individual optimal milking intervals, found by solving the nonlinear programming problem, depend on the 


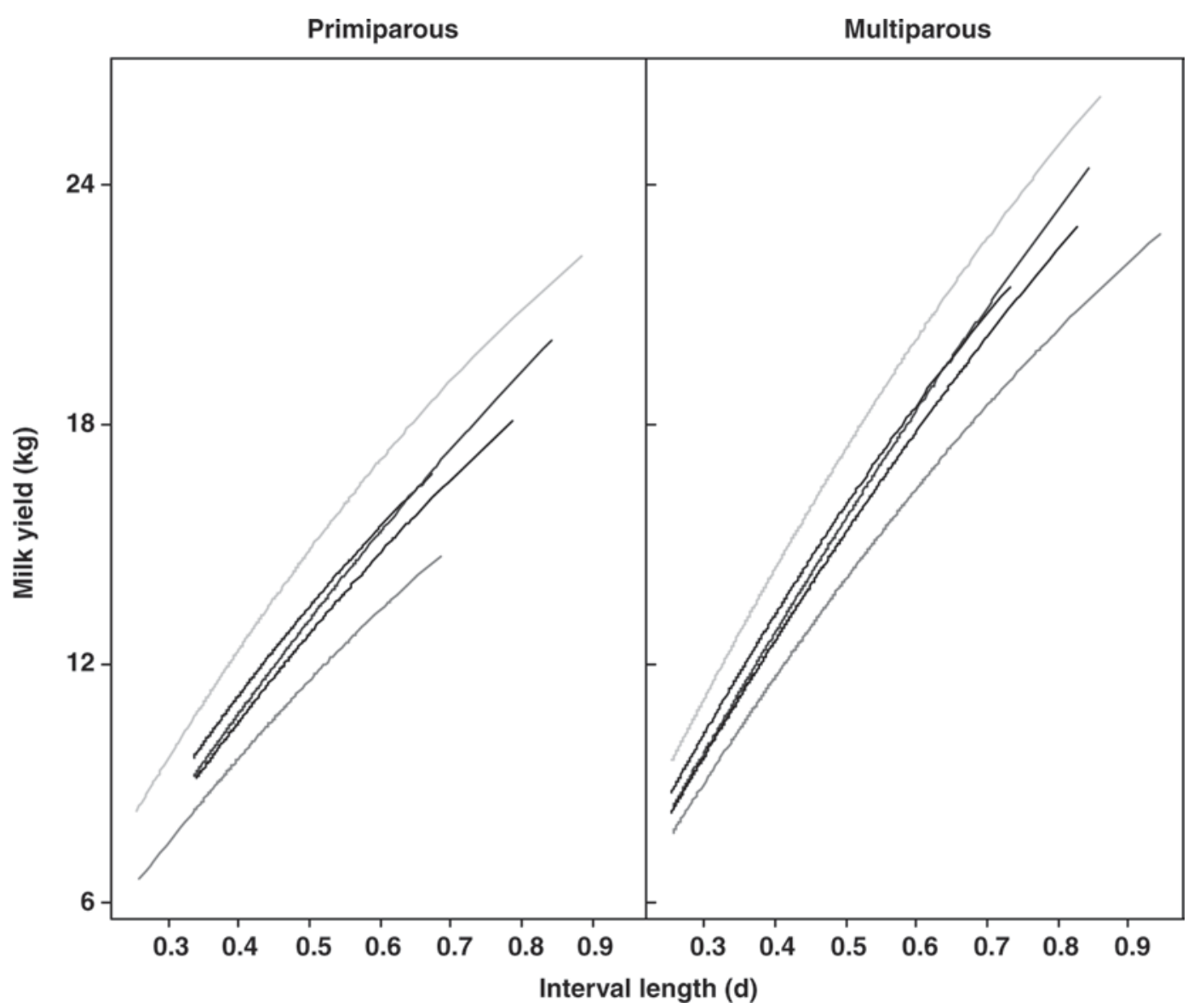

Figure 3. Fitted milk yield per milking versus interval length for different herds (1101, 1201, 1301, 1401, and 1501).

estimated individual parameters: intercept, slope, milk production rate, interval sensitivity, and individual milk price. Table 5 contains results at the herd level after applying individual optimal intervals in comparison with actually realized individual milking intervals.

Applying individual optimal milking intervals to the studied herds resulted, on average, in $5 \%$ lower intervals than realized milking intervals in the actual situation. In other words, without increasing the OR, milking frequency increased with optimal intervals, with a better distribution of the available capacity of the AMS across individual cows. Daily milk yield increased by $1.38 \%$ and daily milk revenues increased by $1.81 \%$. The increase in milk revenues was relatively greater than the increase in daily milk yield, because the individual optimal milking intervals were aimed to maximize daily milk revenues.

The increases in daily milk yield and daily milk revenues were caused by shortening the milking intervals (i.e., increasing the number of milkings). Note that this did not result in an increase in milking duration, whereas the OR was kept constant. Results are given in Table 6, where a distinction is made between the parts of the duration that were related to milk yield (accumulated yield effect) and were not related to milk yield (accumulated intercept).

The application of optimal individual milking intervals resulted in an increase in the total number of milkings per day, at the herd level, of 7 milkings, but in spite of that, the accumulated intercept was reduced by $8 \mathrm{~min}(1 \%)$ in favor of the accumulated yield effect. This shows that optimizing the intervals resulted in milking cows with a low intercept more often than cows with a high intercept.

The results in Table 7 show that by increasing the OR, it is possible to increase daily milk yield and daily milk revenues by shortening the milking interval. Davis et al. (1998) studied the effect of milking interval on milk accumulation in the udder, whereas Bruckmaier and Hilger (2001) studied the effects on milk excretion. These studies showed that short intervals had a negative effect on milk excretion and that lengthening the intervals increased the risk of milk loss. Applying the individual optimal intervals, as proposed in our 

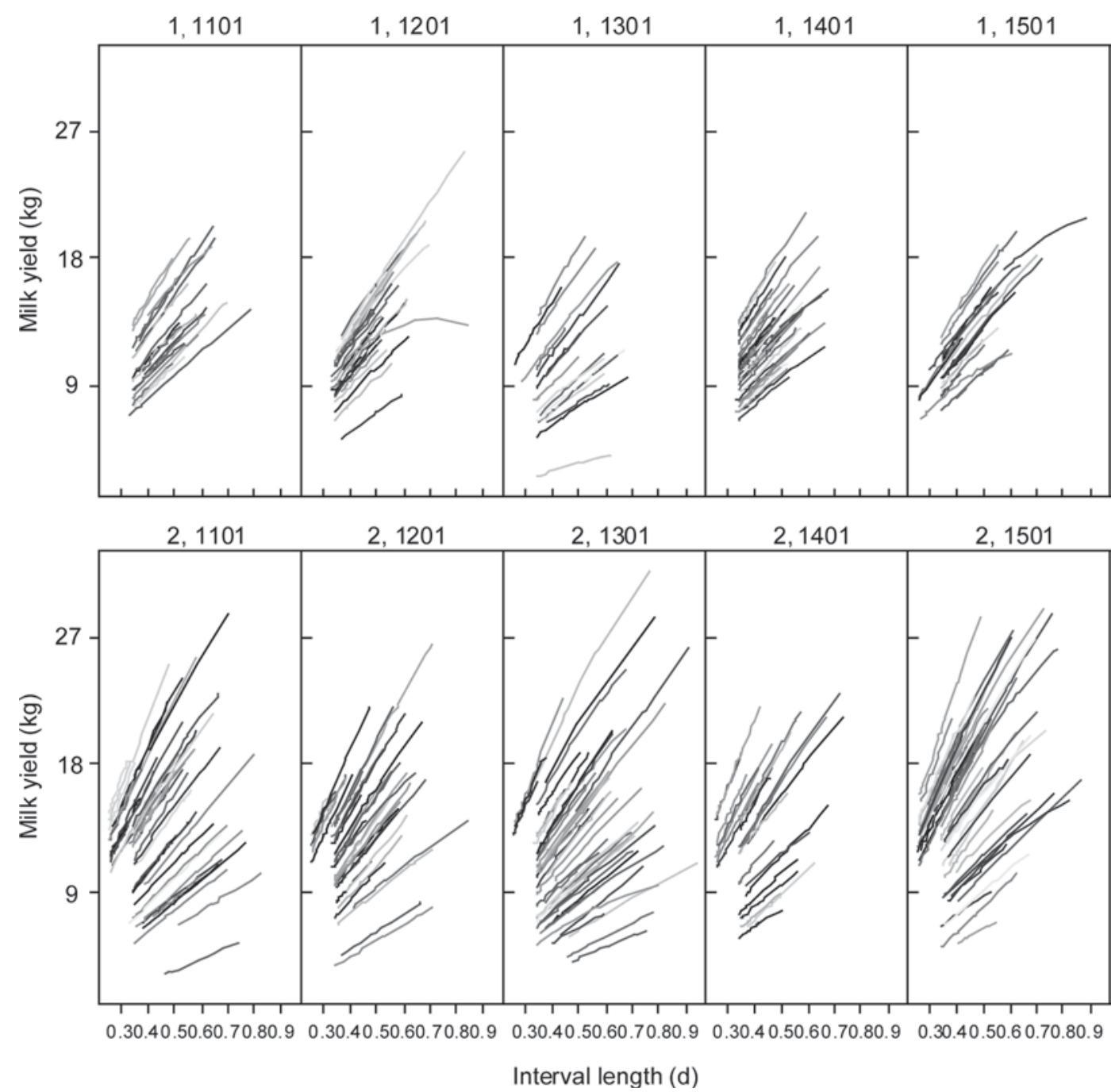

Figure 4. Fitted milk yield per milking versus interval per cow for different herds (left to right). Primiparous (upper row) and multiparous (lower row).

research, will guarantee a good udder fill, thus reducing the risk of negative effects on milk excretion. Milk loss attributable to long intervals is part of the interval sensitivity, which is accounted for in determining the optimal intervals. In our approach, both long and short intervals are avoided, and this may also have positive effects on udder health.

Table 8 shows that increasing the OR resulted in an increase in the number of milkings and in the milking duration. Accordingly, idle time was reduced. The accumulated intercept increased much more than the accumulated yield effect.

The part of milking duration that does not depend on daily milk yield (the accumulated intercept) is a considerable part, anywhere from $30 \%$ to almost $50 \%$, of the total milking duration. This part consists mainly of the time needed for handling. Handling time is required for cleaning the teats, teat detection, and attachment of the teat cups and, to a lesser extent, for identification and entrance and exit of the cows. In this study, we found an average intercept of 2.4 to $3.3 \mathrm{~min} /$ milking per herd, which is in agreement with the handling time of 2.23 min reported by de Koning and Ouweltjes (2000). Hogeveen and Ouweltjes (2001) reported a preparation time of approximately $1 \mathrm{~min} /$ milking, up to $5 \mathrm{~min} /$ milking. Note that preparation time does not include the time a cow needs to exit the AMS. Cooper and Parsons (1999) reported a time of 4.05 min for cows to move through the AMS (excluding machine-on time), based on data from milking trials by Mottram et al. (1995), Sonck (1996), and Rossing (1997). Additionally, these authors used the relationship $t=2.75+0.207 M$, following the method of Clough (1977), for milk-out time. Hence, in total their estimate for handling time 
Table 4. Parameter estimates and standard errors for milking duration

\begin{tabular}{lcc}
\hline Parameter & Estimate & SE \\
\hline Systematic part of the model & & \\
Intercept $\left(\alpha_{0}\right)$ & 3.34 & 0.17 \\
Fixed effect of herd $\left(\tau_{0 k}\right)$ & 0 & - \\
$\quad$ Herd 1101 & -0.483 & 0.224 \\
$\quad$ Herd 1201 & -0.098 & 0.207 \\
$\quad$ Herd 1301 & -0.948 & 0.226 \\
Herd 1401 & -0.506 & 0.222 \\
$\quad$ Herd 1501 & 0.264 & 0.009 \\
Linear effect $\left(\alpha_{1}\right)$ & & \\
Random part of the model & 4.19 & 0.58 \\
Variance intercept $\left(\sigma_{A 0}^{2}\right)$ & & \\
& 0.0322 & 0.0044 \\
Variance linear effect $\left(\sigma_{A 1}^{2}\right)$ & & \\
& 0.444 & 0.010 \\
Residual variance $\left(\sigma_{\delta}^{2}\right)$ & -0.525 & 0.117 \\
Correlation of intercept with linear effect $\left(\rho_{A 01}\right)$ & & \\
\hline
\end{tabular}

was $4.05+2.75=6.8 \mathrm{~min}$, which is approximately twice as long as the estimated intercept in our study. In contrast, the parameter they used for inversed milk flow, $0.207 \mathrm{~min} / \mathrm{kg}$, was lower than the estimated value of $0.264 \mathrm{~min} / \mathrm{kg}$ found in our study. A reduction of handling time will increase the capacity of the AMS (Gygax et al., 2007), and it is recommended that AMS developers pay attention to this aspect.

The counterpart of handling time in the duration of milking is the milk yield-related time (i.e., the yield effect). The yield effect on milking duration time corresponds to machine-on time and depends on technical aspects such as the detachment level, vacuum level, and milk flow-dependent pulsation ratio (Ipema and Hogewerf, 2004). These technical aspects were not considered in this study. Although machine-on time was not measured in this study, the slope parameter can be used as an indication of the reciprocal of the milk flow, and the calculated yield effect gives an indication of machine-on time.

In a simulation model of an AMS developed by Cooper and Parsons $(1998,1999)$, factors depending on the milking interval were used to correct daily milk yield. The factors following the method of Parsons (1988) were based on quantitative studies conducted by Dodd and Griffin (1977). The correction factors are given in Table 9 and are compared with correction factors derived from the parameter estimates presented in Table 3.

Table 9 shows that Parsons (1988) found a much higher effect of milking interval on daily yield. In comparison with our results, the author predicted higher milk yields after short intervals and lower milk yields after long intervals. A possible explanation is that since these studies were conducted by Dodd and Griffin (1977), milk yield per cow has increased, together with an increase in the storage capacity of the udder. Cooper and Parsons (1999) found the maximum profit for a single-stall AMS, relative to conventional milking,

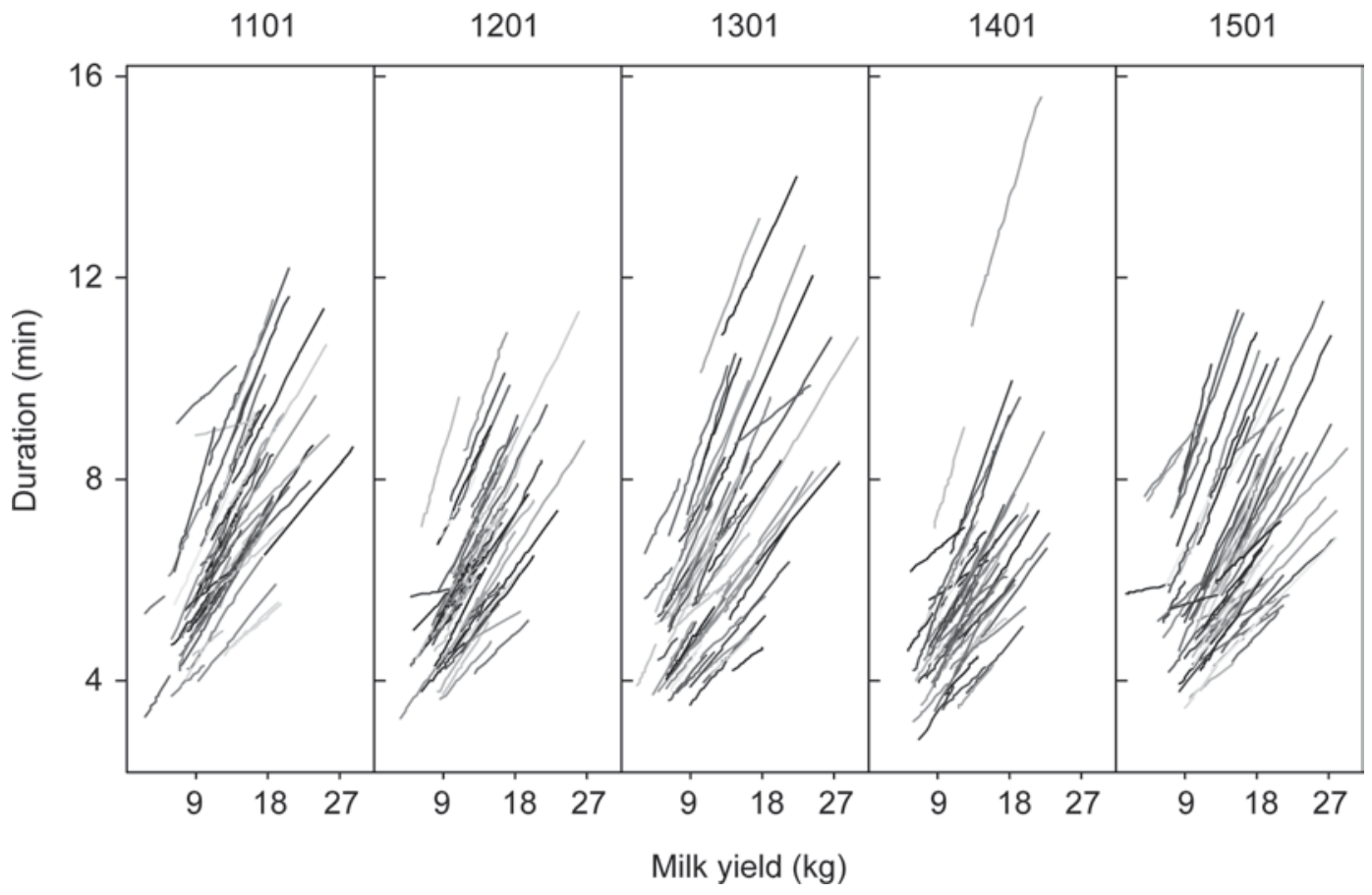

Figure 5. Fitted milk duration versus milk yield per milking per cow for the different herds (left to right: 1101, 1201, 1301, 1401, and 1501). 
Table 5. Results at the herd level for the individual intervals actually realized at the current occupation rates (OR) compared with the results achieved at optimal individual intervals

\begin{tabular}{lcccccc}
\hline Item & Herd 1101 & Herd 1201 & Herd 1301 & Herd 1401 & Herd 1501 & Average \\
\hline Current OR (\%) & 70.3 & 63.0 & 60.1 & 56.5 & 70.7 & 64.2 \\
Milking interval (d) & & & & & & \\
$\quad$ Actual & 0.416 & 0.425 & 0.449 & 0.401 & 0.418 & 0.421 \\
Optimal & 0.411 & 0.416 & 0.431 & 0.371 & 0.379 & 0.400 \\
$\quad$ Relative change (\%) & -1.2 & -2.1 & -4.0 & -7.5 & -9.3 & -5.0 \\
Milk yield (kg/d) & & & & & & \\
$\quad$ Actual & 1,960 & 1,835 & 1,595 & 1,774 & 2,249 & 1,883 \\
Optimal & 1,980 & 1,861 & 1,615 & 1,789 & 2,298 & 1,909 \\
Relative change (\%) & 1.02 & 1.41 & 1.25 & 0.85 & 2.18 & 1.38 \\
Milk revenue (€/d) & & & & & & 458 \\
$\quad$ Actual & 530 & 492 & 430 & 458 & 582 & 498 \\
Optimal & 535 & 499 & 442 & 463 & 596 & 507 \\
Relative change (\%) & 0.94 & 1.42 & 2.79 & 1.09 & 2.41 & 1.81 \\
\hline
\end{tabular}

for a herd of 55 cows. They predicted sharp reductions in profit with increasing herd size. They stated that the decline was caused by a decrease in milk yield as a consequence of longer intervals between milkings.

In the situation at the experimental farm, the capacity of the AMS was not limiting. However, the interval settings by the herdsman (Table 2) were much shorter than the intervals actually realized and were also shorter than the individual optimal intervals (Table 5). The visiting frequency of the cows was too low, so it became necessary to collect the cows and bring them to the AMS to achieve the desired intervals. The management strategy on the research farm was to fetch cows 3 times per day when the actual milking interval exceeded a fixed threshold (e.g., $12 \mathrm{~h}$ ). A better strategy for fetching would be to set the threshold proportional to the individual optimal milking interval to ensure that only the right cows are collected. When short milking intervals are aimed for, the cows have to be collected more frequently. To achieve an OR of $85 \%$, the milking interval should be substantially decreased to $0.238 \mathrm{~d}$, and this is feasible in practice only by fetching the cows more often; consequently, more labor is required for collecting the cows, and the time not related to milk yield is substantially increased.

Alternatively, an OR of $85 \%$ could be achieved by increasing herd size without increasing the milking frequency. To achieve this, the herd size should be increased from 60 to 80 cows, proportional to an increase in the OR from 64 to $85 \%$. Milk yield then increases proportionally to $2,535 \mathrm{~kg} / \mathrm{d}$ and milk revenues increase to $€ 673 / d$. Hence, our research suggests that it is feasible to milk many more cows with a single-stall AMS than was stated by Cooper and Parsons (1999). Increasing the herd size is usually not possible in the actual situation because it depends on the specific farm situation; limiting conditions might arise from land use, housing, or the milk quota.

Increasing the milking frequency and increasing the herd size improve the revenues from automatic milking, but which strategy is the most profitable depends on the costs of producing an extra unit of milk. These costs are not considered here, because this study is mainly focused on optimization at the operational level given the herd size in the actual situation.

This study used milk production data from $1 \mathrm{wk}$ to quantify the variation in milking characteristics between individual cows and to gain insight into the potential benefits of improving the capacity of an AMS. Milk yield and milking duration data during this 1-wk period were used to estimate the individual parameters, representing the actual situation for each cow at that moment during lactation. At other moments during lactation, milk yield and milking duration will probably

Table 6. Number of milkings, milking duration in terms of accumulated intercept, and yield effect across herds for individual milking intervals actually realized compared with optimal individual milking intervals

\begin{tabular}{|c|c|c|c|c|c|}
\hline \multirow[b]{2}{*}{ Individual interval } & \multirow[b]{2}{*}{ Milkings (no.) } & \multicolumn{2}{|c|}{ Accumulated intercept } & \multicolumn{2}{|c|}{ Accumulated yield effect } \\
\hline & & $\min$ & $\%^{1}$ & $\min$ & $\%^{1}$ \\
\hline Actual & 148 & 433 & 30 & 491 & 34 \\
\hline Optimal & 155 & 425 & 29 & 499 & 35 \\
\hline Change & 7 & -8 & -1 & 8 & 1 \\
\hline
\end{tabular}

${ }^{1} 100 \%=1 \mathrm{~d}=1,440 \mathrm{~min}$. 
Table 7. Herd-level results for optimal individual intervals at different occupation rates $(\mathrm{OR})^{1}$

\begin{tabular}{|c|c|c|c|c|c|c|c|}
\hline Item & Herd 1101 & Herd 1201 & Herd 1301 & Herd 1401 & Herd 1501 & Average & Relative change (\%) \\
\hline OR $70 \%$ & 0.413 & 0.339 & 0.332 & 0.250 & 0.386 & 0.334 & -20.1 \\
\hline OR $75 \%$ & 0.365 & 0.300 & 0.297 & 0.222 & 0.337 & 0.295 & -29.9 \\
\hline OR $85 \%$ & 0.292 & 0.241 & 0.243 & 0.180 & 0.265 & 0.238 & -43.5 \\
\hline \multicolumn{8}{|c|}{ Milk yield $(\mathrm{kg} / \mathrm{d})$} \\
\hline OR $70 \%$ & 1,978 & 1,890 & 1,662 & 1,873 & 2,292 & 1,939 & 3.0 \\
\hline OR $85 \%$ & 2,046 & 1,928 & 1,704 & 1,920 & 2,387 & 1,997 & 6.1 \\
\hline \multicolumn{8}{|c|}{ Milk revenue $(€ / d)$} \\
\hline OR $70 \%$ & 534 & 507 & 447 & 484 & 594 & 513 & 3.0 \\
\hline OR $75 \%$ & 541 & 511 & 452 & 489 & 604 & 519 & 4.2 \\
\hline OR $80 \%$ & 548 & 514 & 456 & 493 & 612 & 525 & 5.3 \\
\hline OR $85 \%$ & 552 & 516 & 459 & 497 & 619 & 529 & 6.1 \\
\hline
\end{tabular}

${ }^{1}$ The change is relative to results achieved with actually realized individual intervals.

be different. As a consequence, the parameter estimates for each cow should be updated regularly during lactation. This is possible by following an approach based on dynamic linear models (West and Harrison, 1997). With a dynamic approach, the optimal intervals are updated regularly and are automatically adapted to a changing herd size and changing herd characteristics over time.

Individual variation in the milk production response to feeding was not taken into account in this study. Feed intake and milk production were assumed to be constant during the short period of data collection. Moreover, $1 \mathrm{wk}$ is considered too short to allow for estimating the effects of feeding. Individual variation in the milk production response to feeding was studied by André et al. (2010). Within a dynamic approach, it is possible to estimate the individual milk production response to concentrate feeding continuously from realtime process data (André et al., 2007). The optimal individual milking interval should be determined in combination with the optimal individual concentrate supply to maximize the gross margin of milk revenues minus feeding costs.

\section{CONCLUSIONS}

This study showed that marked variation exists between individual cows in the effect of interval length on daily milk yield and, consequently, on milking duration. The efficiency of an AMS can be increased by applying individual optimal milking intervals; milk revenues increased from $€ 498$ to $€ 507 / \mathrm{d}$ for a herd of approximately 60 cows without increasing the OR. By increasing the OR from 64 to $85 \%$, a further increase in milk revenues to $€ 529 / d$ is possible. Alternatively, when an OR of $85 \%$ is obtained by increasing the herd from 60 to 80 cows, milk revenues increase to $€ 673 / \mathrm{d}$. For practical implementation on farm, a dynamic approach is recommended, in which parameter estimates regarding the effects of interval length on milk yield and of milk yield on milking duration are updated regularly and the response in milk production to concentrate intake is also taken into account.

\section{ACKNOWLEDGMENTS}

The authors are grateful to Edwin Bleumer for gathering the data. This project was funded by the Dutch

Table 8. Number of milkings, accumulated intercept and yield effect, and milking duration averaged across herds at different occupation rates $(\mathrm{OR})$

\begin{tabular}{|c|c|c|c|c|c|c|c|}
\hline \multirow[b]{2}{*}{$\mathrm{OR}^{1}(\%)$} & \multirow[b]{2}{*}{ Milkings (no.) } & \multicolumn{2}{|c|}{ Accumulated intercept $(a)$} & \multicolumn{2}{|c|}{ Accumulated yield effect $(b)$} & \multicolumn{2}{|c|}{$\begin{array}{l}\text { Milking duration } \\
\qquad(a+b)\end{array}$} \\
\hline & & $\min$ & $\%^{1}$ & $\min$ & $\%^{1}$ & $\min$ & $\%^{1}$ \\
\hline 70 & 185 & 502 & 35 & 506 & 35 & 1,008 & 70 \\
\hline 75 & 210 & 568 & 39 & 512 & 36 & 1,080 & 75 \\
\hline 80 & 235 & 635 & 44 & 517 & 36 & 1,152 & 80 \\
\hline 85 & 260 & 703 & 49 & 521 & 36 & 1,224 & 85 \\
\hline
\end{tabular}

${ }^{1} 100 \%=1 \mathrm{~d}=1,440 \mathrm{~min}$. 
Table 9. Correction factors for daily milk yield depending on milking interval

\begin{tabular}{lcc}
\hline $\begin{array}{l}\text { Milking } \\
\text { interval (d) }\end{array}$ & $\begin{array}{c}\text { Following } \\
\text { Parsons (1988) }\end{array}$ & $\begin{array}{c}\text { Based on parameter } \\
\text { estimates }\end{array}$ \\
\hline 1.00 & 0.69 & 0.84 \\
0.50 & 1.00 & 1.00 \\
0.33 & 1.14 & 1.05 \\
0.25 & 1.20 & 1.08 \\
\hline
\end{tabular}

Commodity Board for Dairy Products (Zoetermeer) and the Dutch Ministry of Agriculture, Nature and Food Quality (Den Haag). We also thank the reviewers for their helpful comments.

\section{REFERENCES}

André, G., W. Ouweltjes, R. L. G. Zom, and E. J. B. Bleumer. 2007. Increasing economic profit of dairy production utilizing individual real time process data. Pages 179-186 in Precision Livestock Farming '07. S. Cox, ed. Wageningen Academic Publishers, Wageningen, the Netherlands.

André, G., P.B.M. Berentsen, G. van Duinkerken, B. Engel, and A.G.J.M. Oude Lansink. 2010. Economic potential of individual variation in milk yield response to concentrate intake of dairy cows. J. Agric. Sci. (accepted)

Bijl, R., S. R. Kooistra, and H. Hogeveen. 2007. The profitability of automatic milking on Dutch dairy farms. J. Dairy Sci. 90:239248.

Bruckmaier, R. M., and M. Hilger. 2001. Milk ejection in dairy cows at different degrees of udder filling. J. Dairy Res. 68:369-376.

Clough, P. A. 1977. Milking in cowsheds and parlours. In Machine Milking. C. C. Thiel and F. H. Dodd, ed. Natl. Inst. Res. Dairying, Shinfield, UK.

Cooper, K., and D. J. Parsons. 1998. A simulation model of an automatic milking system applying different management strategies. J. Agric. Eng. Res. 69:25-33.

Cooper, K., and D. J. Parsons. 1999. An economic analysis of automatic milking using a simulation model. J. Agric. Eng. Res. 73:311-321.

Davis, S. R., V. C. Farr, P. J. A. Copeman, V. R. Carruthers, C. H. Knight, and K. Stelwagen. 1998. Partitioning of milk accumulation between cisternal and alveolar compartments of the bovine udder: Relationship to production loss during once daily milking. J. Dairy Res. 65:1-8.

Delamaire, E., and J. Guinard-Flament. 2006. Longer milking intervals alter mammary epithelial permeability and the udder's ability to extract nutrients. J. Dairy Sci. 89:2007-2016.

de Koning, C. J. A. M., and W. Ouweltjes. 2000. Maximising the milking capacity of an automatic milking system. Pages 38-46 in Robotic Milking, Proc. Int. Symp. H. Hogeveen and A. Meijering, ed. Wageningen Pers, Wageningen, the Netherlands. de Koning, K., and J. Rodenburg. 2004. Automatic milking: State of the art in Europe and North America. Pages 27-37 in Automatic Milking: A Better Understanding. A. Meijering, H. Hogeveen, and C. J. A. M. de Koning, ed. Wageningen Academic Publishers, Wageningen, the Netherlands.

Dodd, F. H., and T. K. Griffin. 1977. Milking routines. Pages 000-000 in Machine Milking. C. C. Thiel and F. H. Dodd, ed. Natl. Inst. Res. Dairying, Shinfield, UK.

France, J., and J. H. M. Thornley. 1984. Mathematical Methods in Agriculture: A Quantitative Approach to Problems in Agriculture and Related Sciences. Butterworths, London, UK.

Genstat Committee. 2006. GenStat Release 9 Reference Manual. VSN Int., Hemel Hempstead, UK.

Gygax, L., I. Neuffer, C. Kaufmann, R. Hauser, and B. Wechsler. 2007. Comparison of functional aspects in two automatic milking systems and auto-tandem milking parlors. J. Dairy Sci. 90:4265-4274.

Hogeveen, H., and W. Ouweltjes. 2001. Sensors and management support in high-technology milking. J. Anim. Sci. 81(Suppl. $3): 1-10$.

Ipema, A. H., and P. H. Hogewerf. 2004. Effects of milking machine parameters on the mean milk flow rate in a robotic milking system. Pages 450-456 in Automatic Milking: A Better Understanding. A. Meijering, H. Hogeveen, and C. J. A. M. de Koning, ed. Wageningen Academic Publishers, Wageningen, the Netherlands.

Mottram, T. T., R. C. Hall, C. S. Spencer, and C. J. Allen. 1995. The role of the cow in automatic teat cup attachment . J. Dairy Sci. $78: 1873-1880$

Ouweltjes, W. 1998. The relationship between milk yield and milking interval in dairy cows. Livest. Prod. Sci. 56:227-232.

Parsons, D. J. 1988. An initial economic assessment of fully automatic milking of dairy cows. J. Agric. Eng. Res. 40:199-214.

Robinson, G. K. 1991. That BLUP is a good thing: The estimation of random effects. Stat. Sci. 6:15-32.

Rosenthal, R. E. 2006. GAM-system-A User's Guide. GAM-Syst. Dev. Corp., Washington, DC

Rossing, W. 1997. Freiheit oder "Weltraumfahrer"? Zwei Melkrobotersysteme im Vergleich [Liberty or astronaut? A comparison of two robotic milking systems]. Landtechnische Z. 10:82-86

Searle, S. R., G. Casella, and C. E. McCullough. 1992. Variance Components. Wiley, New York, NY.

Sonck, B. R., and H. W. J. Donkers. 1995. The milking capacity of a milking robot. J. Agric. Eng. Res. 62:25-38.

Sonck, B. R. 1996. Labour organization on robotic milking dairy farms. PhD Thesis. Agric. Univ. Wageningen, Wageningen, the Netherlands.

Stelwagen, K. 2001. Effect of milking frequency on mammary function and shape of the lactation curve. J. Dairy Sci. 84(E Suppl.):E204E211.

Vetharaniam, I., S. R. Davis, M. Upsdell, E. S. Kolver, and A. B. Pleasants. 2003. Modeling the effect of energy status on mammary gland growth and lactation. J. Dairy Sci. 86:3148-3156.

West, M., and J. Harrison. 1997. Bayesian Forecasting and Dynamic Models. 2nd ed. Springer-Verlag, New York, NY. 